\title{
Pentingnya Lingkungan dalam Pembelajaran Bahasa Indonesia
}

\author{
Oleh : Afifah Tu Sahada \\ afifahtshd24@gmail.com
}

Masalah lingkungan bukanlah suatu hal yang baru. Masalah lingkungan seperti pembakaran hutan, pencemaran lingkungan, pemburuan binatang dan tumbuhan yang dilindungi merupakan permasalahan yang dari dulunya sudah ada, dan terus berlanjut tanpa ada penyelesaian. Masalah lingkungan ini disebabkan oleh aktivitas manusia yang ceroboh dan intensif di daerah alami untuk meningkatkan kualitas hidup mereka. Kerusakan lingkungan menyebabkan serangkaian masalah dengan alam sumber daya, iklim, polusi, makanan, dan ekonomi, sehingga terjadi ketidakseimbangan dalam lingkungan hidup. Salah satu upaya penyelesaian masalah lingkungan yang berkelanjutan ini adalah dengan menanamkan sejak dini kepada generasi muda tentang pentingnya menjaga lingkungan. Hal-hal kecil seperti tidak membuang sampah sembarangan, menggunakan air seperlunya, dan lain sebagainya merupakan langkah awal yang bisa dilakukan. Menanamkan rasa tanggung jawab dan kesadaran akan menjaga lingkungan dapat dilakukan di sekolah dengan menerapkan materi lingkungan dalam pembelajaran. Salah satu pembelajaran yang dapat dikaitkan dengan materi lingkungan adalah pembelajaran bahasa.

Menurut Uyar dan Ensar (dalam Ramadhan et al, 2019), menggunakan tema lingkungan dalam pembelajaran teks dapat memicu minat siswa dalam mempelajari bahasa dan secara berimplikasi dapat meningkatkan pengetahuan siswa tentang lingkungan hidup. Pembelajaran berbasis lingkungan bertujuan untuk membuat siswa berpartisipasi dalam melindungi lingkungan. Tidak memandang lingkungan sebagai sesuatu yang bisa dieksploitasi untuk kepentingan pribadi, tetapi sebagai aset berharga yang layak dilindungi untuk kelangsungan hidup manusia. Oleh karena itu, peting untuk mengembangkan pengetahuan tentang lingkungan, kesadaran lingkungan dan perubahan perilaku terhadap lingkungan. Pendidikan lingkungan dapat membantu siswa memikirkan kembali hubungan antara manusia dan lingkungan, memahami lingkungan, menyadari masalah lingkungan dan mempertimbangkan masalah lingkungan yang berkaitan dengan kehidupan (Ramadhan et al, 2019).

Menurut Obasoro, Oyinloye, dan Ilensami (dalam Ramadhan et al, 2019), siswa perlu memiliki pengalaman dalam mengambil inisiatif sehubungan dengan persyaratan yang mendesak 
di bidang tantangan global dan masyarakat. Sejalan dengan itu, menurut Bergman B,G (dalam Ramadhan et al, 2019), guru memainkan peran penting dalam mengajarkan pendidikan lingkungan hidup. Guru dapat memberikan materi lingkungan kepada siswa agar siswa dapat memahami contoh yang tepat yang bisa ditemui di sekitarnya. Selain guru, siswa juga memiliki peranan yang penting dalam proses pembelajaran. Karena tanpa adanya respon atau tindakan pengaplikasian materi yang diberikan oleh guru, maka tujuan dari pembelajaran tersebut tidak akan tercapai.

Berdasarkan permasalahan yang dijabarkan di atas, penulis melakukan penelitian mengenai pentingnya lingkungan dalam pembelajaran bahasa Indonesia. Penelitian dilakukan dengan membuat 10 pernyataan dalam bentuk angket google form. Hasil yang didapat dari penelitian ini adalah sebagai berikut. Yang menjawab pertanyaan ada 34 orang, 82,4 \% perempuan, 17,6\% laki-laki. Dari 34 orang, 26 orang dari Universitas Negri Padang, 3 orang dari Universitas Muhammadiyah Bukittinggi, 2 orang dari Universitas Islam Riau, 1 orang STKIP Bukittinggi, 2 orang pelajar.

Pertanyaan pertama, Dalam pembelajaran bahasa indonesia materi lingkungan sangat penting untuk dipelajari, 58,8\% menjawab sangat setuju, 41,2\% menjawab setuju, $0 \%$ menjawab sangat tidak setuju, $0 \%$ menjawab tidak setuju. Pertanyaan kedua, Lingkungan merupakan faktor yang mempengaruhi pendidikan di sekolah, 61,8\% menjawab setuju, 38,2\% menjawab sangat setuju, $0 \%$ menjawab sangat tidak setuju, $0 \%$ menjawab tidak setuju. Pertanyaan ketiga, suasana di lingkungan sekolah harus diciptakan seoptimal mungkin untuk mendukung siswa agar merasa nyaman dan betah untuk belajar, 73,5\% menjawab sangat setuju, 26,5\% menjawab setuju, $0 \%$ menjawab sangat tidak setuju, $0 \%$ menjawab tidak setuju. Pertanyaan keempat, Materi lingkungan dalam pembelajaran bahasa Indonesia berkaitan dengan penggunaan bahasa Indonesia dalam kehidupan sehari-hari, 61,8\% menjawab setuju, 29,4\% menjawab sangat setuju, $8,8 \%$ menjawab tidak setuju. $0 \%$ menjawab sangat tidak setuju.

Pada pertanyaan kelima, keuntungan adanya materi lingkungan dalam pembelajaran bahasa indonesia adalah siswa dapat menghargai dan menjaga lingkungan dengan baik, 61,8\% menjawab sangat setuju, 38,2\% menjawab setuju, $0 \%$ menjawab sangat tidak setuju, $0 \%$ menjawab tidak setuju. Pertanyaan keenam, materi lingkungan dapat memudahkan siswa dalam memahami materi bahasa indonesia, 70,6\% menjawab setuju, 26,5 menjawab sangat setuju, 2,9\% menjawab tidak setuju, 0\% menjawab sangat tidak setuju. Pertanyaan ketujuh, lingkungan dapat 
mengembangkan imajinasi siswa dalam pembelajaran bahasa indonesia, 69,7\% menjawab setuju, 30,3\% menjawan sangat setuju, $0 \%$ menjawab sangat tidak setuju, $0 \%$ menjawab tidak setuju. Pertanyaan kedelapan, keuntungan adanya materi lingkungan dalam pembelajaran bahasa indonesia adalah siswa dapat menghargai dan menjaga lingkungan dengan baik, 52,9\% menjawan sangat setuju, 47,1\% menjawab setuju, $0 \%$ menjawab sangat tidak setuju, $0 \%$ menjawab tidak setuju. Selanjutnya pertanyaan kesembilan, lingkungan dapat dijadikan diskusi dalam pembelajaran bahasa indonesia, 64,7\% menjawab setuju, 36,3\% menjawab sangat setuju, 0\% menjawab sangat tidak setuju, $0 \%$ menjawab tidak setuju. Pertanyaan terakhir yaitu pembelajaran dapat dijadikan tema dalam pembelajaran bahasa indonesia, 58,8 menjawab setuju, $38,2 \%$ menjawan sangat setuju, 3\% menjawab tidak setuju, $0 \%$ menjawab sangat tidak setuju.

Dari hasil penelitian penulis di atas, dapat disimpulkan bahwa materi lingkungan sangat penting untuk diterapkan dalam pembelajaran bahasa Indonesia. Materi lingkungan memudahkan siswa dalam memamahami materi bahasa Indonesia dengan baik, menambah wawasan siswa, serta dapat membangun kecerdasan ekologis siswa. Materi lingkungan merupakan materi yang sangat erat kaitannya dengan kehidupan sehari-hari. Oleh karena itu, dengan materi lingkungan guru bisa dengan mudah mencari contoh relevan yang membuat siswa lebih paham akan materi yang diberikan, sehingga dapat membantu guru dalam mengimplikasikan materi bahasa Indonesia.

Dalam (Ramadhan, et al (2019) ), sorang memiliki kewajiban yang sama untuk menjaga lingkungan. Untuk dapat menjaga lingkungan dibutuhkan pemahaman dan pengetahuan tentang lingkungan. Guru berperan penting dalam menyampaikan ilmu tersebut kepada siswa, karena siswa merupakan generasi penerus yang bertugas menjaga lingkungan. Pendidikan lingkungan dapat diintegrasikan ke dalam pelajaran lain, salah satunya adalah pembelajaran bahasa. Pengintegrasian dapat dilakukan dengan menggunakan tema tentang lingkungan dalam pembelajaran teks. Melalui teks yang dipelajari, siswa dapat mempelajari bahasa dan mendapatkan pengetahuan lingkungan melalui isi teks yang dibacakan. Berdasarkan hal tersebut, maka penting bagi guru untuk memiliki pengetahuan lingkungan dan sikap peduli lingkungan. Jika guru tidak memiliki pengetahuan dan sikap, maka pembelajaran bahasa menjadi kurang bermakna. Guru harus mampu mendesain pembelajaran bahasa dengan mengintegrasikan berbagai topik, salah satunya pendidikan lingkungan. Anda dapat menggunakan teks yang berhubungan dengan lingkungan atau menggunakan metode pembelajaran yang sesuai. 
Penelitian ini dapat digunakan sebagai bahan evaluasi bagi semua pihak khususnya calon guru bahasa untuk dapat menambah pengetahuannya tentang pendidikan lingkungan. Dengan bertambahnya pengetahuan tersebut maka dapat menumbuhkan sikap peduli lingkungan dan dapat meningkatkan keterampilan dalam mengintegrasikan lingkungan. 


\section{DAFTAR PUSTAKA}

Bergman B G 2016 Assessing impacts of locally designed environmental education projects on students' environmental attitudes, awareness, and intention to act Environmental Education Reseach22 (4) 480-503.

Buldur, A. and Ömeroglu, E. (2018). An examination of the relationship between pre- school children's and their teacher' attitute and awareness towards the environment Journal of Education and Learning 7(2) 221-9.

Hauchild S, Poltavthenko E and Stoller F L 2012 Going green: Menging environmental education and language instruction English Teaching Forum Number 2 2-13.

Jacobs G M and Cates K.(2012). Global education in second language and teaching. International Journal of Physica 1 and Social Sciences 2 1-22.

Mbete, A. M. (2015). Pembelajaran Bahasa Berbasis Lingkungan: Perspektif Ekolinguitik. RETORIKA: Jurnal Ilmu Bahasa, 1(2),352-364.

Munawaroh, S. 2014. "Pengaruh Lingkungan Sekolah Terhadap Siswa Dalam Pembelajaran Bahasa Indonesia Kelas X Madrasah Aliyah (MA) Daarul Falahiyyah Kampung Panggang, Kecamatan Cisoka, Kabupaten Tanggerang”. Fakultas Ilmu Tarbiyah dan Pendidikan. UIN Jakarta: Jakarta

Obasoro C B, Oyinloye O A and Ilensami A A 2013 The importance of environmental education to secondary education level in Akure South local goverment area, Ondo State Nigeria African Research Review7 (4) 298-306.

Ramadhan, S., Sukma, E., \& Indriyani, V. (2019). Environmental education and disaster mitigation through language learning. IOP Conference Series: Earth and Environmental Science, 314, pp. 1-9.

Tulalessy, Q. D. (2016). Pembelajaran Bahasa Berbasis Lingkungan Sebagai Upaya Membangun Kecerdasan Ekologis. Jurnal Triton Pendidikan, 1(1), 51-56.

Uyar Y and Ensar F 2016 Does mother tongue education support development of environmental literacy in Turkey? An analysis of Turkish course book International Journal of Environmental \& Science Education 11(1) 1-8 